\title{
Modeling Thermal-Hydrological Response of the Unsaturated Zone at Yucca Mountain, Nevada, to Thermal load at a Potential Repository.
}

\author{
C.B. Haukwa, Yu-Shu Wu and G. S. Bodvarsson
}

Earth Science Division, Lawrence Berkeley National Laboratory, Berkeley CA 94720, USA

\begin{abstract}
This paper presents a numerical study on the response of the unsaturated zone (UZ) system of Yucca Mountain to heat generated from decaying radioactive wastes emplaced at the proposed repository. The modeling study is based on the current thermal-hydrological (TH) mountain-scale model, which uses a locally refined 2D north-south cross section and dual-permeability numerical approach. The model provides a prediction of the mountain-scale $\mathrm{TH}$ response under the thermal-load scenario of $1.45 \mathrm{~kW} / \mathrm{m}$, while accounting for future climatic changes and the effects of drift ventilation. The TH simulation results show that ventilation of the repository drifts has a large impact on thermal-hydrologic regimes and moisture-flow conditions at the repository. In both cases, with and without ventilation, the TH model predicts dry or reduced liquid saturation near the drifts for over 1,000 years, during which liquid flux through the drifts is reduced to either zero or less than the ambient flux. Without ventilation, the model predicts higher temperatures at the repository, but no major moisture redistribution in the UZ except in the areas very near the heated drifts.
\end{abstract}

Keywords: Thermal hydrological behavior; Unsaturated zone flow and transport; Radioactive waste disposal; Drift Ventilation, Thermal and Moisture distribution, and Liquid reflux. 


\section{Introduction}

Numerical modeling studies have been performed to better understand the TH behavior of the unsaturated zone (UZ) system at Yucca Mountain, Nevada, following potential emplacement of heat-generating waste packages. This is part of the ongoing site characterization of Yucca Mountain as a potential underground repository for high-level radioactive waste. Quantitative investigation of fluid flow, heat transfer, and radionuclide transport at Yucca Mountain is an essential step for conducting these site-characterization studies. Numerical models of coupled-heat and fluid-flow processes provide information for designing the repository and the engineered barrier system, and for assessing the system's performance for the operating period.

Numerical modeling has played a crucial role in understanding the fluid movement in the UZ, and in the evaluation of the effects of hydrogeologic, thermal, and geochemical conditions on the waste-disposal system. Whereas laboratory and field experiments are limited in both space and time, numerical modeling provides a means to study physical processes on large temporal and spatial scales relevant to understanding $\mathrm{TH}$ behavior associated with nuclear waste disposal in a geologic formation. In particular, a numerical TH model of the Yucca Mountain can be used to assess the impact of heat on the UZ flow and transport processes over a period of thousands of years on the mountain scale. Such a model allows for prediction of evolution of temperature, moisture distribution, and changes in liquid reflux in the UZ and near the drifts that may control the long-term integrity of the waste canisters by influencing corrosion rates. On the other hand, a dry repository drift environment assures that even if containment canisters fail, the radionuclides, which would be primarily transported through the liquid phase, remain within the repository drifts for thousands of years.

Continual characterization of the Yucca Mountain site has resulted in a highly detailed geological framework model of the UZ at Yucca Mountain and improved conceptual and numerical models for UZ flow and transport. This, together with newly estimated surface infiltration maps, has led to a better calibrated set of rock and flow properties. The progress made in improving the UZ flow model, based on new evidence and field data, necessitates updating the associated TH model. Similarly, design changes in the operating mode of the potential repository (e.g., the 
thermal load, its distribution, and the forced or natural ventilation operations), affect the TH response of the UZ system.

$\mathrm{TH}$ models also allow for prediction of the potential for mechanically or geochemically induced changes in UZ properties. Elevation in temperature affects rock stress and may lead to permeability changes, affecting flow behavior especially near the drifts. Similarly, changes in temperature can result in chemical changes that also affect the flow and transport properties of the UZ rocks. For example, the Calico Hills zeolitic rock units that underlie the potential repository horizon can impede the transport of radionuclides from the potential repository to the water table, because of their low permeability and high sorptivity. However, when heated for long periods of time at temperatures exceeding $90^{\circ} \mathrm{C}$, the flow and transport properties of these rocks can be altered, thus directly impacting their ability to retard radionuclide transport. In addition, the flow properties of the Paintbrush unit (PTn), a unit above the repository horizon, may also be altered when heated at elevated temperatures for long periods, leading to different percolation patterns at the repository horizon.

Many field tests have been conducted within the UZ in an effort to characterize the UZ. These tests are designed to obtain parameters required in development and validation of predictive UZ numerical models. These include tests to characterize the fracture network and to measure permeability and seepage characteristics of the UZ under ambient conditions. Thermal experiments, both at laboratory scale and within the underground exploratory tunnels, have been conducted to investigate both $\mathrm{TH}$ and $\mathrm{THC}$ (thermal-hydrologic-chemical) processes that occur when heat is applied to the unsaturated tuffs. However, such tests can only be performed at a few locations and typically last a few months to a couple of years. Although these tests are extremely useful for studying conceptual aspects of flow and transport processes over a short term, they have limited use in validation of $\mathrm{TH}$ processes that are on a large, mountain scale and last several thousand years. For example, the UZ mountain-scale model domain covers over 40 $\mathrm{km}^{2}$, and has a depth of 500-700 m. The potential repository environment under thermal load needs to be characterized over a period of 10,000 years. Heater tests conducted in small areas within the drifts for a few months or few years cannot provide sufficient data for validation of the TH models over large spatial and temporal scales. 


\section{Previous Work}

Numerical models have been used to analyze thermal-hydrologic conditions associated with heat-releasing nuclear waste buried in geological repositories since the early 1980s. Previous modeling studies associated with the potential repository at Yucca Mountain were summarized in Haukwa et al. (1999). Significant progress has been made in developing TH models from simple one-dimensional (1D) models of the thermal loading effects to two-dimensional (2D) or three-dimensional (3D) mountain-scale models, employing both the effective-continuum method (ECM) and dual-permeability numerical formulations for handling fracture-matrix interactions. Haukwa et al. (1999) reports on the development of a TH model of Yucca Mountain that incorporates both 2D and 3D ECM numerical models and a 2D dual-permeability model, based on the 1996 UZ flow and transport model (Bodvarsson, et al., 1996). Although the $2 \mathrm{D}$ grids in that modeling study were more refined than the $3 \mathrm{D}$ grids, they were still relatively coarse, with only a $50 \mathrm{~m}$ spacing and not including any local refinement for individual drifts at the repository. The simulations however, showed that the TH models based on dual-permeability grids predict a smaller boiling zone than the ECM models and provide a more realistic representation of fluid fracture flux. Additional characterization of UZ under thermal load has been conducted at Lawrence Livermore laboratory (Buscheck, 1998; Buscheck et. al., 1999; and CRWMS M\&O, 2000) to provide a detailed evolution of near-field processes and assess the effects of model scale and large-scale heterogeneity.

Several modeling studies (Pruess and Tsang, 1993, 1994, Haukwa, 2001) have also been conducted to investigate heat-driven flow processes on a small scale to assess the effects of spatial heterogeneity. In a heterogeneous fractured hydrogeologic system such as the tuffs at Yucca Mountain, liquid percolation associated with rock heating within the UZ may be dominated by highly localized phenomena. This may include "fast" channelized flow along preferential paths in fractures and local ponding. TH models, using geostatistical methods to include spatial variation in fracture permeability, predict that with the present mean infiltration conditions, thermal load can still result in dry drift conditions for thousands of years, because of a strong capillary barrier and vaporization potential (Haukwa, 2001). These TH models coupled with models reactive flow and transport provide the basis for prediction of migration of radionuclides below potential repository in a thermally perturbed environment (Viswanathan, et. al. 1999). 
The mountain-scale TH models are developed from many laboratory and field experiments involving TH processes. Tsang and Birkholzer (1999) present field results and numerical models of the Single Heater Test at Yucca Mountain. Birkholzer and Tsang (2000) present a detailed evaluation of the thermal testing results after 1 year of a planned 8-year test and show that the field test results and numerical-model simulations are in good agreement.

\section{Objectives}

This paper discusses the development of a mountain-scale TH model of Yucca Mountain using a numerical grid that accurately represents the design thermal load configuration at the repository. The model quantifies both near-drift and mountain-scale TH processes, and assesses several issues important in the evaluation of potential repository performance. These issues include the extent of the boiling zone, the magnitude and duration of the thermally enhanced liquid and gas flux in the near- and far-fields, and the evolution of moisture and temperature distribution in the UZ near the drifts and within pillars. The TH model is also used to predict the potential for temperature-induced changes in flow and transport properties within the Paintbrush (PTn) and Calico Hills (CHn) nonwelded hydrogeological units and at the water table.

\section{Modeling Approach}

\subsection{Mathematical and Numerical Approach}

As in several previous numerical models discussed above, the TH models developed in this study use the integralfinite-difference mathematical formulation employed in the TOUGH2 family of codes (Pruess 1987; 1991). Coupled flow of heat and fluids in fractured geological media is handled using the dual-continuum approach (Warren and Root, 1963; Pruess and Narasimhan, 1985; Wu and Pruess, 1988). The van Genuchten model (van Genuchten, 1980) is employed to describe the relationships between capillary pressure, liquid relative permeability, and saturation for flow in fracture and matrix systems, respectively. Heat is transferred primarily by conduction through the matrix and by convection through the high-permeability fractures. In addition, the fracture-matrix properties calibrated for the different UZ hydrogeological units are incorporated in the studies. There is a special treatment used in the TH models for the numerical problem, as capillary suction pressure rises to unrealistically high levels when liquid drops 
to zero (caused by the drying of fractures and matrix continua). To avoid the unphysical capillary pressures, the capillary pressure-saturation relationship used in the TH models is linearly extrapolated to zero liquid saturation from a point near the residual liquid saturation. Furthermore we use the modified Brooks and Corey relationship (Brooks and Corey, 1966) to calculate the gas relative permeability.

Simulations were conducted over total period of 100,000 years. The equation of state module EOS3 (Wu and Haukwa, 1999; Pruess 1987) of the TOUGH2 code was used for modeling water, air, and heat flow. This module contains the constitutive relationships that describe the thermodynamic properties of water (enthalpy, density, and viscosity) as functions of temperature and pressure, and also allows for selection of the appropriate relative permeability and capillary pressure versus saturation relationships.

\subsection{Conceptual Model}

The conceptual hydrogeological model for describing TH processes at Yucca Mountain is based on the current conceptual model of the UZ flow model. In this hydrogeological conceptual model, the UZ system consists of multi-layered hydrogeologic units determined primarily by the degree of welding in Yucca Mountain tuffs (Montazer and Wilson 1984). The proposed repository is located within the welded tuffs of the Topopah Spring middle nonlithophysal unit. These tuffs have very small pores and matrix permeability is very low but the unit is intensely fractured. Most of the liquid is therefore held in the matrix by capillary forces, while most of the flow is through the well-connected fractures, where the permeability is several orders of magnitude higher than the matrix. Under the ambient geothermal and moisture conditions, fractures at the repository horizon are relatively dry (liquid saturation less than $1.5 \%$ ), while the matrix system is very wet (with liquid saturation at about $90 \%$ ).

Heat generated by decaying high level radioactive waste buried in such a system will increase the temperature of the repository rocks substantially. It will also cause drying of both matrix and fracture continua by a combination of vaporization and vapor diffusion process (caused by temperature gradient). These vapors may condense in lower temperature regions above the drifts and within the drift pillars. The condensed liquid may flow back towards the drifts, by the combined action of gravity and capillary pressure. When such flow occurs through preferential paths or 
by gravity drainage, it will contact only a small fraction of the fracture-matrix surface, in a fingering type of flow that can break the thermal barrier and lead to early wetting of containment canisters.

The numerical approach for modeling fractured systems with this type of fluid flow still involves volume averaging and continuum concepts. To model coupled fluid and heat flow with fracture-matrix interaction, we use a dualpermeability formulation (Warren and Root, 1963; Doughty et al. 1999) to represent the fractured media. In the dual-permeability formulation, one fracture and one matrix element overlap at each location of rock volume. Flow in the fractured system occurs within the network of fractures, within matrix blocks and between fractures and the matrix. Fingering liquid flow in fractures is modeled using the active fracture concept (Liu et al., 1998) in which fracture-matrix liquid flow resulting from the fingering flow is controlled through the active fracture parameter $\gamma$. Key input data used in the development of the TH model of the fractured system therefore include:

- UZ hydrogeological model, repository design, and numerical grid.

- Fracture and matrix hydraulic properties (permeability, van Genuchten $\alpha$ and $m$, and active fracture parameter $\gamma$, for each UZ model layer.

- Rock physical and geometrical properties (porosity, fracture frequency, and fracture surface area) for each UZ model layer.

- Thermal properties (grain density, wet and dry thermal conductivity, grain specific heat, and tortuosity coefficients) for each UZ model layer.

- Designed thermal load, surface infiltration rates, boundary and initial conditions.

\subsection{Numerical Grids}

The TH simulations were conducted using a refined 2D cross-sectional grid in the middle of the proposed repository at Yucca Mountain. The numerical grid is based on the Geologic Framework Model of the mountain, with hydrogeological units defined in the 3D UZ ambient flow model grid. Figure 1 shows a plan view of 3D UZ grid and the 2D cross section. The potential repository is located between the Solitario Canyon fault and the Ghost Dance faults and extends from Boreholes H-3 in the south to UZ-14 in the north. Vertically, the potential repository is located at an elevation of 1,070 masl, within the middle nonlithophysal unit of the Topopah Spring welded tuff. 
Figure 2 shows the numerical grid along the 2D N-S cross section and the hydrogeological units along the cross section. The average dip of layers along this cross-section is about $5^{\circ}$ (less 1 in 10). Non-orthogonal lateral connections are used to represent these gently sloping layers. This numerical grid approximation neglects the contribution of cross-terms in the numerical discretization due to vertical separation of laterally connected nodes. Post-modeling analysis of the effect of cross-terms using a grid with orthogonal interfaces shows negligible effect on the numerical solution when the slope is less than $10^{\circ}$. For these gently sloping layers the cross-terms connections contribute less that $6 \%$ to the flux and have little effect on both steady state and transient solutions. The small interface area cross-connections may introduce aspect ratio and grid orientation effects (Pruess, 1991b) We also use the non-orthogonal lateral connections because the calibrated flow properties used in this UZ TH model are based on a numerical grid that neglects the contribution of cross-terms.

In this grid, lateral spacing is equal to $1 / 4$ of the drift spacing $(81 \mathrm{~m})$, to ensure spatial separation of the drift nodes and to provide for adequate spatial resolution of ambient liquid flux between drifts. A 5-m thick grid layer bounded above and below by $5-\mathrm{m}$ thick layers represents the potential repository horizon. At the repository elevation, the grid is locally refined with a $5-\mathrm{m}$ wide drift element in every fourth column of the grid. This allows for discrete distribution of the applied thermal load into the drifts. With local refinement, the resulting numerical grid has a total of 29,974 elements and 71,189 connections in the dual-permeability formulation.

\subsection{Thermal Load}

The initial average heat yield of the waste packages for the high temperature design is $1.45 \mathrm{~kW} / \mathrm{m}$. Over time the effective heat load within the drifts will reduce by the combined effect of ventilation and natural decay. In 50 years the natural decay accounts for a $60 \%$ decline in the initial heat yield. To cool the repository during the period when the heat yield is high, a combination of forced and natural ventilation will be used. Although ventilation will initially remove both heat and vapor the rapid development of completely dry conditions around drift means little vapor will be carried away by the ventilation system for most of ventilated period. In this case ventilation can be represented by a simple reduction in the thermal load. In the repository design considered, cooling of the waste 
package by ventilation is assumed to remove $70 \%$ of the heat during the 50 years pre-closure period. We use this ventilation factor and natural decay factor to develop a time-dependent net heat load table that is used as the as a heat-source in the potential repository drifts. To quantify the effects of ventilation, we model both "no ventilation" and "ventilation" scenarios.

\subsection{Boundary and Ambient Conditions}

The numerical grids use the top of the Tiva Canyon (TCw) unit as the top boundary. This coincides with the ground surface at most locations, except in areas with thick alluvium cover (where the top is at the alluvium- $\mathrm{TCw}$ contact).

Fixed temperature conditions are assigned along this top boundary. The temperature at any given top boundary element is calculated from measured near-surface reference temperatures, using a dry-adiabatic cooling relationship between atmospheric temperature and elevation (Driscoll, 1986). Also fixed at this boundary is gas pressure, corresponding to the atmospheric pressure at the boundary node elevation. The water table is used as the bottom boundary for fluid flow and has a fixed pressure of 0.92 bar. To allow for the prediction of temperature changes at the water table, the bottom temperature boundary is extended 1,000 meters below the water table. The temperature at the extended boundary was fixed at $65^{\circ} \mathrm{C}$.

These boundary conditions are used to obtain a steady-state flow and heat flow condition with the present day mean infiltration first. Then the steady-state flow solution is used as the initial condition for the TH models. The simulated average initial temperature at the water table $\left(730\right.$ masl) is between 30 to $33^{\circ} \mathrm{C}$ within the potential repository domain, which is in agreement with the calibrated temperature distribution at the water table. The average initial temperature at the repository horizon is about $23^{\circ} \mathrm{C}$.

\subsection{Infiltration Rates}

Three infiltration scenarios covering the simulated period of 100,000 years were used. These are the mean presentday climate over the period 0-600 years, the monsoon climate over the period $600-2,000$ years, and the glacial transition climate over the period 2,000-100,000 years. The average net-infiltration rate along the cross section is 
$4.8 \mathrm{~mm} /$ year for the mean present-day infiltration scenario, $11.3 \mathrm{~mm} /$ year for the mean monsoon climate average infiltration, and $16.9 \mathrm{~mm} / \mathrm{year}$ for the mean glacial-transition climate. The TH simulations started with the present day mean present-day infiltration rate followed by step changes in infiltration rates at 600 years and at 2000 years to that of the corresponding climate.

\section{Results of Simulations}

We discuss the results in terms of changes in temperature, liquid saturation, and liquid flux and compare the results of ventilated and non-ventilated thermal-load scenarios. In particular, attention is given to the TH model results that directly quantify the near- and far-field performance environment of the potential repository.

\subsection{Temperature}

The evolution of the temperature distribution during thermal loading provides an estimate of the area affected by the heat at the potential repository. The numerical model can provide the predicted distribution at any desired time during the thermal-loading period. Figure 3 shows the distribution of simulated temperature along the 2D crosssection after 1,000 years of thermal load (a) without ventilation, and (b) with ventilation. The plots show that high temperatures possibly leading to boiling are predicted only in the area immediately above and at the potential repository horizon. The higher temperatures and larger hot zones are predicted for the no-ventilation case. The temperature distribution above the repository is irregular, primarily because of variation in infiltration and elevation of the top boundary. On the other hand, at a lateral distance of 100 meters or more from the potential repository, no substantial increase in temperature is calculated in either case. For example, the predicted maximum temperature is $37^{\circ} \mathrm{C}$ at 100 meters north of the potential repository and about $40^{\circ} \mathrm{C}$ at 100 meters south, without ventilation. The temperatures at 200 meters away from the potential repository remain at near ambient conditions throughout the simulation. This response suggests that the convection mode of heat transfer (i.e., boiling and rapid fracture flow in the vertical direction) is dominant near the potential repository.

A detailed evaluation of temperature changes can be obtained by plotting the evolution of temperature profiles in a column within the potential repository domain. The plots of vertical temperature profiles in a column at the center of 
the potential repository (Location \#1, see Figure 2) are shown in Figure 4. The high temperature gradients at 1250$1270 \mathrm{~m}$ represent the top of the boiling zone located near the base of the PTn. Without ventilation (Figure 4a), the model predicts that temperature within the drifts could rise to over $250^{\circ} \mathrm{C}$ after both matrix and fracture elements of the drifts become completely dry. In this case, a two-phase "heat pipe" zone at $97^{\circ} \mathrm{C}$ develops above the potential repository drift and extends out to 50 meters after 500 years. At 1,000 years, temperatures at drift are still above boiling conditions, although temperatures above the drifts begin to decline while temperatures below the drifts continue to rise. With ventilation (Figure 4b) no such high-temperature peak develops, and temperatures everywhere are much lower than in the no-ventilation case. However, maximum temperature for a large part within the drifts does rise to a boiling condition $\left(97^{\circ} \mathrm{C}\right)$, although in a few locations, temperatures rise to about $110^{\circ} \mathrm{C}$ (CRWMS M\&O, 2000a).

Without ventilation, temperatures at some locations at the base of the PTn (elevation 1,250-1,270 masl) may rise to boiling conditions, increasing the potential for temperature-induced property changes in the PTn, especially within the low-infiltration areas. With ventilation, temperatures at the base of PTn are predicted to rise by $20-25^{\circ} \mathrm{C}$ from the ambient condition to an average of $40-45^{\circ} \mathrm{C}$. At the top of the $\mathrm{CHn}$ unit (elevation 907 masl) the model predicts maximum temperature of $70-75^{\circ} \mathrm{C}$, between 2,000 and 7,000 years, therefore posing little potential for temperatureinduced property changes within the zeolites of the $\mathrm{CHn}$ unit. At the water table, the models predict a maximum temperature of $65-70^{\circ} \mathrm{C}$, compared with the average ambient temperature of $30^{\circ} \mathrm{C}$.

A plot of the evolution of temperature along the middle section of the potential repository horizon is presented in Figure 5a (without ventilation) and in Figure 5b (with ventilation). The peaks correspond to the center of the thermal-load drifts, with the maximum temperatures estimated at the drifts and minimum temperatures within the middle of the pillars. Figure 5a shows that the temperatures without ventilation at the potential repository horizon rise to above boiling conditions $\left(97^{\circ} \mathrm{C}\right)$ between 5 and 10 years. At ten years, most of the drifts are at a temperature of $100^{\circ} \mathrm{C}$, but the temperatures rise to $235-240^{\circ} \mathrm{C}$ after 50 years. At this time, however, the temperatures are predicted to rise to $260-300^{\circ} \mathrm{C}$ in the completely dried-out drifts at the northern end of the potential repository, where the surface infiltration rate is nearly zero. After 50 years, the temperatures in the drifts decline rapidly (due to re-wetting), driven by strong capillary suction and gravity drainage. At 100 years, maximum temperature within the 
drifts has dropped to $160-180^{\circ} \mathrm{C}$ and continues to decline. After 500 years, maximum temperature within the drifts is $120-135^{\circ} \mathrm{C}$, and after 1,000 years the temperature is $100-110^{\circ} \mathrm{C}$ within the drifts. The maximum temperature at the center of the drift pillars is about $97^{\circ} \mathrm{C}$ after $500-1,000$ years, which reduces to $65{ }^{\circ} \mathrm{C}$ after 10,000 years. Therefore, even without ventilation, the predicted maximum temperatures at the center of the pillars between the drifts do not exceed boiling temperature.

Figure $5 \mathrm{~b}$ shows the temperatures in the middle section of the potential repository horizon with ventilation. The model predicts much lower temperatures within the drifts, resulting from rapid cooling or removal of heat by ventilation. Maximum temperatures at most locations along the potential repository horizon will not exceed boiling temperature (Figure 5b), although at localized areas with low ambient infiltration, the temperature may rise above $100^{\circ} \mathrm{C}$. The maximum temperature in the center of the drift pillars is $85^{\circ} \mathrm{C}$ after 1,000 years. After 10,000 years the temperature drops to about $65^{\circ} \mathrm{C}$ within the pillars and to about $70^{\circ} \mathrm{C}$ at the drifts. Note that similar temperatures are predicted at 10,000 years without ventilation (Figure 5a), showing that the long-term temperature response is not affected by the 50 years of ventilation.

\subsection{Saturation}

Changes in liquid saturation (or moisture) condition are important because they indicate how long the dryout period at the potential repository will last. They also identify the onset of rewetting processes and the subsequent potential for corrosion and release of radionuclides at the potential repository horizon. Changes in liquid saturation can also be used to assess the potential for desaturation-induced changes in porosity and hydraulic conductivity (for example, in the zeolitic units). Changes in liquid saturation were analyzed using matrix liquid saturation. This was done because in both scenarios, the fractures in the drifts at the potential repository horizon are completely dry within the first few years of thermal loading and do no rewet until 1,000 years after thermal loading begins.

Figure 6 shows contour plots of liquid saturation in rock matrix at 1,000 years (a) without ventilation, and (b) with ventilation. The plots show significant decrease in matrix liquid saturation occurring near the drift only. Matrix continuum in the rest of the UZ remains at near-ambient conditions except for the areas directly above the drifts, 
where liquid saturation increases a little as a result of condensation. Figure 7 shows the matrix liquid saturation profiles at location \#1 and Figure 8 shows the corresponding saturation along a section of the repository horizon. Without ventilation, the models predict completely dry conditions (Figures $7 \mathrm{a}$ and $8 \mathrm{a}$ ) for all the drifts between 10 and 50 years, which remain dry for up to 1,000 years in several locations. During this period, an area of reduced matrix liquid saturation develops and extends up to $100 \mathrm{~m}$ above and below the potential repository horizon. Within the drift pillars, the matrix liquid saturation drops to a minimum of 0.4 after 500 years.

With ventilation (Figures $7 \mathrm{~b}$ and $8 \mathrm{~b}$ ), completely dry matrix conditions are predicted only at a few isolated locations under low surface-infiltration rates. Vertically (Figure 7b) the zone of reduced matrix saturation extends to about 50 $\mathrm{m}$ above and below the drifts. The matrix saturation in several drifts with high percolation flux recovers to above 0.9 at 1,000 years (Figure 8b). After 5,000, years the matrix liquid saturation is almost completely recovered to the ambient liquid saturation. The matrix liquid saturation within the pillars remains at near-ambient conditions and is controlled mainly by changes in climate. With and without ventilation, the simulations predict that the liquid saturation at a lateral distance more than 50 meters away from the repository remains at near-ambient conditions.

\subsection{Fluid Flow}

Analysis of the liquid flux helps to estimate the quantity and duration of enhanced liquid flux (resulting from thermal load) that may potentially contact the waste canisters (in the near-field environment) and cause releasing radionuclides. Liquid flow towards the potential repository can be enhanced by a decrease in saturation at drift rock, which leads to an increase in capillary pressure. The liquid flux can also be enhanced by an increase in saturation, resulting from drainage of condensate from increased liquid relative permeability. The heat within drifts can vaporize or boil this liquid reflux, particularly at early times when the heat yield from radioactive decay is still high. The vaporization leads to increased gas flux, which may cause localized condensation above the drifts, and drainage towards the drifts or through the drift pillars. Because over $95 \%$ of liquid flow at the potential repository horizon is through fractures, only changes in fracture liquid flux are discussed. 
Figure 9 shows profiles of the evolution of predicted liquid-flux through the fractures at the center of the potential repository, with and without ventilation. Because of the decrease in liquid saturation (dry out) zone within the drifts, both models predict high liquid flux near the drifts that is primarily capillary-pressure driven. Without ventilation, Figure 9a, the predicted maximum liquid flux rises $360 \mathrm{~mm} /$ year (the plots here show liquid flux scale of up to 200 $\mathrm{mm} /$ year for clarity) at 10 years, but declines to less than $30 \mathrm{~mm} /$ year at 500 years. With ventilation (Figure $9 \mathrm{~b}$ ) much lower liquid flux is predicted. The average liquid flux near the potential repository rises to only $60 \mathrm{~mm} / \mathrm{year}$ at 10 years. After 500 years, the predicted maximum liquid flux is about $40 \mathrm{~mm} / \mathrm{year}$.

Figure 10a shows the fracture liquid flux at the potential repository horizon without ventilation. Note that vertical liquid flux at Location \#1 (Figure 9) is averaged over the entire column area and hence is smaller. Along the crosssection, the liquid flux is calculated for each of the three locally refined elements within the drift column at the repository. The result is a much higher flux within the central (drift) element because it is dryer and accounts for most of the mass flux, but has only $1 / 4$ of the column area. Without ventilation, the fracture liquid, calculated based on this smaller drift area, rises to between $1,250-1,600 \mathrm{~mm} /$ year after 10 years. This liquid flux then drops to zero, as the fractures in the drifts become completely dry (between 10 and 50 years). As the fractures rewet between 500 and 1,000 years, the fracture liquid flux recovers (Figure 10a). At 1,000 years fracture liquid flux at several locations is about $20-50 \mathrm{~mm} / \mathrm{year}, 2$ to 5 times higher than the mean infiltration rate for the monsoon climate. The simulation results also show an increase in fracture liquid flux in the pillars between the drifts, resulting from condensate drainage. At around 500 years (Figure 10a), the average fracture flux between drifts is about $20 \mathrm{~mm} /$ year, about 5 times higher than the average infiltration rate.

Although ventilation lasts only 50 years, it results in changes in liquid flux that last for several hundred years. Ventilation leads to much lower induced liquid flux because the effective thermal load is only $30 \%$ of the total load during the period in which the heat yield of the emplaced waste is the highest. The heat removed by ventilation results in a delay in the dry-up of the fracture-matrix continua, and a lower liquid flux at the potential repository horizon. The predicted fracture liquid flux at the potential repository horizon rises to a maximum of 270-300 $\mathrm{mm} /$ year at 10 years. At 100 years (50 years after the end of ventilation), the liquid flux towards the drifts is only 10 $\mathrm{mm} /$ year. However, flux recovers to over $150 \mathrm{~mm} /$ year at 500 years as a result of increased drying of matrix and re- 
wetting of the fractures. After 5,000 years, the fracture continuum at the potential repository horizon is almost completely rewetted, and liquid flux returns to the ambient flux (Figure 10b). In this case, fracture liquid flux through the pillars between the drifts remains at or above ambient conditions. The predicted liquid flux between the drifts is 15 to $20 \mathrm{~mm} /$ year (about 2 to 3 times the ambient flux) at 500 years (Figure 10b). Beyond 500 years, the fracture liquid flux in the pillars is controlled primarily by the changes in climate.

\section{Summary and Conclusions}

The effect of radioactive-waste-generated heat on mountain-scale TH processes at Yucca Mountain is investigated using the numerical model. The model uses a 2D numerical grid and incorporates currently calibrated flow properties. Fracture-matrix flow is modeled using a dual-permeability approach based on the active fracture concept for considering possible fingering channels in fractures. In addition, the model explicitly represents each drift at the potential repository and implements a thermal load of $1.45 \mathrm{~kW} / \mathrm{m}$, with a 50 -year pre-closure ventilation. The model accounts for expected future climatic changes in net-infiltration rates. The 2D numerical grid is sufficiently refined to provide prediction of both near-drift and mountain-scale, long-term TH behavior results from thermal load within the drifts. The performance presented here is typical of expected conditions at the center of a fully loaded repository drift. It is expected that 3D effects will lower overall temperatures, reduce the extent of drying, particularly towards the edges of the repository. In additional this model neglects any temperature and THC effects on flow, which at the grid resolution used in this study are reasonable assumptions.

The TH model predicts no adverse effects of heat on the repository environment particularly with ventilation. The TH model results indicate that heat removed by ventilation and effective infiltration rates control the boiling and rewetting TH processes at the potential repository. The results are dependent on ability of the natural or forced ventilation system to achieve a uniform design level of cooling. With no ventilation, the model predicts development of a two-phase heat-pipe (boiling) region at the areas above the potential repository and drift temperatures exceeding $100^{\circ} \mathrm{C}$ for hundreds of years. The models predict that temperatures may be elevated to more than $250^{\circ} \mathrm{C}$ within the completely dry drifts in areas under low surface infiltration. In this case, boiling may occur 
even within the pillars and last up to 1,000 years. Ventilation cooling by $70 \%$, results in cooler and but still dry drift environment in which temperatures are predicted to rise to boiling conditions only in the immediate area of the drifts. Temperature may rise to $110^{\circ} \mathrm{C}$ at drifts with low ambient liquid infiltration flux. In this case, temperatures in the pillars are predicted to rise to an average of $80-85^{\circ} \mathrm{C}$.

In both cases, with and without ventilation, the $\mathrm{TH}$ model predicts a nearly $30-35^{\circ} \mathrm{C}$ temperature increase at the water table to an average of $60-65^{\circ} \mathrm{C}$. At the top of the $\mathrm{CHn}$, the predicted maximum temperature is $70-75^{\circ} \mathrm{C}$, between 2,000 and 7,000 year, and hence there is minimal potential for temperature-induced property changes in this unit. Above the repository, temperatures within the PTn are predicted to rise to a maximum of $70-75^{\circ} \mathrm{C}$ without ventilation and to an average of $40-45^{\circ} \mathrm{C}$ with ventilation, indicating minimal potential for temperature-induced property changes within the PTn. In both cases, temperatures at a lateral distance of more than $100 \mathrm{~m}$ outside the potential repository are expected to remain at near-ambient conditions.

The TH model predicts that heating of the potential repository drifts will result in hot and dry conditions within the drifts that may last for hundreds of years. Without ventilation, most of the rock mass surrounding the drifts is predicted to become completely dry and remain so for over 1,000 years. With ventilation, although the TH model does not predict completely dry fracture-matrix conditions for all the drifts, most drifts are predicted to remain dry for hundreds of years. In both cases the fractures at the potential repository drifts are predicted to completely dry up and remain dry for hundreds of years. The matrix and fracture liquid saturation within the pillars is predicted to remain high and (at several locations) increase to above the ambient liquid saturation because of vapor condensation. Vertically, the zone of substantially reduced matrix liquid saturation extends to $50 \mathrm{~m}$ directly above and below the drifts with ventilation, and up to $100 \mathrm{~m}$ without ventilation, except in areas of high surface infiltration.

Heating at drifts is predicted to result in large liquid reflux, primarily through the fractures driven by capillary suction and gravity drainage. These back flow rates may rise to two to three orders of magnitude higher than the ambient percolation flux at the repository drifts. However, these large refluxes are confined to a period of less than 100 years. At this time, predicted fracture liquid reflux may exceed 1,250-1,600 mm/year without ventilation and 270-300 mm/year with ventilation. In both cases, however, ample heat exists within the potential repository drifts 
for vaporizing all the back-flow liquid. Therefore, the back-flow liquid is unlikely to seep directly into the drifts. With ventilation, the models predict that liquid flow through the pillars will not be significantly affected by repository heat for most of the thermal-loading period. However, in some locations, the flow may be enhanced by condensate drainage for first several hundred years. The results therefore show that ventilation significantly affects repository performance, affecting both the maximum temperatures within the drifts and the potential for seepage. Data on efficiency of the ventilation system is required to fully quantify these effects. For example if ventilation removes $80 \%$ for the heat for 300 years (cool repository design) boiling will be completely suppressed, but completely dry-drift conditions will develop, although the extent of dry-out zone will be small. The predicted completely dry-drifts with no seepage, indicates that for the thermal load considered, waste container degradation by corrosion will be minimal, even with ventilation. During this dry period, radionuclides released by container failure cannot be transported below the drifts.

\section{Acknowledgments}

The authors would like to thank H.H. Liu for his review of the manuscript. This work was supported by the Director, Office of Civilian Radioactive Waste Management, U.S. Department of Energy, through Memorandum Purchase Order EA9013MC5X between Bechtel SAIC Company, LLC and the Ernest Orlando Lawrence Berkeley National Laboratory (Berkeley Lab). The support is provided to Berkeley Lab through the U.S. Department of Energy Contract No. DE-AC03-76SF00098

\section{References}

Birkholzer, J.T. and Tsang, Y.W., 2000. Modeling the thermal-hydrologic processes in a large underground heater test in partially saturated tuff. Water Resources Research, 36 (6): 1431-1447.

Bodvarsson, G.S., Bandurraga, T.M. (Editors), 1996. Development and Calibration of the Three-Dimensional SiteScale Unsaturated-Zone Model of Yucca Mountain, Nevada, Yucca Mountain Site Characterization Project Milestone OBO2, LBNL Report-39315, Lawrence Berkeley National Laboratory, Berkeley, California. 
Brooks, R.H. and Corey, A.T., 1966. Properties of Porous Media Affecting Fluid Flow. Journal of Irrigation and Drainage Division: Proceedings of the American Society of Civil Engineers, 92 (IR2): 61-88. American Society of Civil Engineers, Washington, D.C.

Buscheck, T.A., J. Gansemer, J.J. Nitao and Deloranzo. 1999. Multi-scale Near-Field thermodynamic Analysis of Alternative Designs for the Potential Repository at Yucca Mountain. In Materials Research Society Symposium Proceedings Vol. 556, pp. 615-622, Editors: MRS Publishing, Warrendale, P.A.

Buscheck, T.A. 1998. Thermohydrological models. Chapter 23 in E.L. Hardin (ed.), Near-field/Altered Zone Report, UCRL-ID-129179, LLNL, Livermore, CA.

CRWMS M\&O, 2000. Multiscale Thermohydrological Model. ANL-EBS-MD-000049 REV 00 ICN 01. Las Vegas Nevada, CRWMS M\&O ACC: MOL20001201.0103.

Doughty, C. 1999. Investigation of conceptual and numerical approaches for evaluating moisture, gas, chemical, and heat transport in fractured unsaturated rock. Journal Of Contaminant Hydrology, 38 (1-3): 69-106. Elsevier Science, Amsterdam, The Netherlands.

Driscoll, F. G., 1986. Groundwater and Wells. Chapter 4 of Weather Patterns and Hydrological Cycle, pp. 50, 2nd Edition. Johnson Filtration Systems, St. Paul Minnesota.

Finsterle, S., 1998. ITOUGH2 V3.2 Verification and Validation Report. Report LBNL-42002, Lawrence Berkeley National Laboratory, Berkeley, California.

Haukwa, C.; Wu, Y.-S.; and Bodvarsson, G.S., 1999. Thermal loading studies using the Yucca Mountain unsaturated zone model. Journal of Contaminant Hydrology, 38 (1-3): 217-255.

Haukwa, C.; Tsang Y.W.; Wu, Y.-S.; and Bodvarsson, G.S., 2001. Effect of Heterogeneity in Fracture Permeability 
on the Potential for Liquid Seepage into a Heated Emplacement Drift of the Potential Repository. Journal of Contaminant Hydrology (this Volume).

Klavetter, E.A. and Peters, R.R., 1986. Estimation of Hydrologic Properties of an Unsaturated Fractured Rock Mass. Report SAND84-2642, Sandia National Laboratories, Albuquerque, New Mexico.

Liu, H.H.; Doughty, C.; and Bodvarsson, G.S., 1998. An Active Fracture Model for Unsaturated Flow and Transport in Fractured Rocks. Water Resources Research, 34 (10): 2633-2646.

Montazer, P. and Wilson, W.E., 1984. Conceptual Hydrologic Model of Flow in the Unsaturated Zone, Yucca Mountain, Nevada. Water Resources Investigations Report 84-4355, 84-4345, U.S. Geological Survey, Denver, Colorado.

Pruess, K., 1987. TOUGH User's Guide. Nuclear Regulatory Commission, Report NUREG/CR-4645. Report LBL20700, Lawrence Berkeley National Laboratory, Berkeley, California.

Pruess, K., 1991. TOUGH2-A General Purpose Numerical Simulator for Multiphase Fluid and Heat Flow. Report LBL-29400, Lawrence Berkeley National Laboratory, Berkeley, California.

Pruess, Karsten (1991). Grid Orientation and Capillary Pressure Effects in the Simulation of Water Injection Into Depleted Vapor Zones. Geothermics, Pergammon, Vol 20, Num 5, pp.257-277.

Tsang, Y.W. and Birkholzer, J.T., 1999. Predictions and Observations of the Thermal-Hydrological Conditions in the Single Heater Test. Journal of Contaminant Hydrology: 38 (1-3): 385-425.

Viswanathan, H.S., Robinson, B.A., Valochi, A.J. and Triay, I.R., 1998. A reactive Models of Neptunium Migration from the Potential Repository at Yucca Mountain, Journal of Hydrology, 209, 251-280, 1998

Van Genuchten, M., 1980. A closed-form equation for predicting the hydraulic conductivity of unsaturated soils. Soil Science Society of America Journal, 44 (5): 892-898. 
Warren, J.E., and Root, P.J., 1963. The behavior of naturally fractured reservoirs. Soc. Pet. Eng. J., Transactions, AIME, 228: pp. 245-255

Wu, Y.-S. and Pruess, K., 1988. A multiple-porosity method for simulation of naturally fractured petroleum reservoirs, SPE Reservoir Engineering, 3: 327-336.

Wu, Y.-S. 1996. On the Effective Continuum Method for Modeling Multiphase Flow, Multicomponent Transport and Heat Transfer in Fractured Rock. LBNL-42720, Lawrence Berkeley National Laboratory, Berkeley, California.

Wu, Y.-S., Haukwa, C. and Bodvarsson, G.S., 1999. A Site-Scale Model for Fluid and Heat Flow in the Unsaturated Zone of Yucca Mountain, Nevada. Journal of Contaminant Hydrology 38 (1-3): 185-215

Wu, Y.-S. and Haukwa, C., 1999. TOUGH2 v. 1.4 and T2R3D v. 1.4 Verification and Validation Report. Lawrence Berkeley National Laboratory, Berkeley, California.

\section{Figure Captions:}

Figure 1. Plan view of the UZ 3D grid, showing the location of the potential repository and the 2D NS cross section. Locations \#1 is used for detail profile plots.

Figure 2. 2D vertical cross section grid, showing lateral and vertical discretization along the 2D NS cross section and indicating the location of the potential repository and the hydrogeologic unit layering.

Figure 3. Temperature distribution along the 2D cross section at 1,000 years: (a) no ventilation and (b) with ventilation.

Figure 4. Temperature variation with time at Location \#1: (a) no ventilation (b) with ventilation. 
Figure 5. Temperature variation along a section of the potential repository horizon: (a) no ventilation and (b) with ventilation

Figure 6. Matrix liquid saturation (SL) along the 2D cross section grid at 1,000 years: (a) no ventilation and (b) with ventilation.

Figure 7. Matrix liquid saturation at Location \#1: (a) no ventilation and (b) with ventilation.

Figure 8. Matrix liquid saturation along a section of the potential repository horizon: (a) no ventilation and (b) with ventilation.

Figure 9. Fracture liquid reflux at Location \#1: (a) no ventilation and (b) with ventilation.

Figure 10. Fracture liquid reflux along a section of the potential repository horizon: (a) no ventilation and (b) with ventilation. 


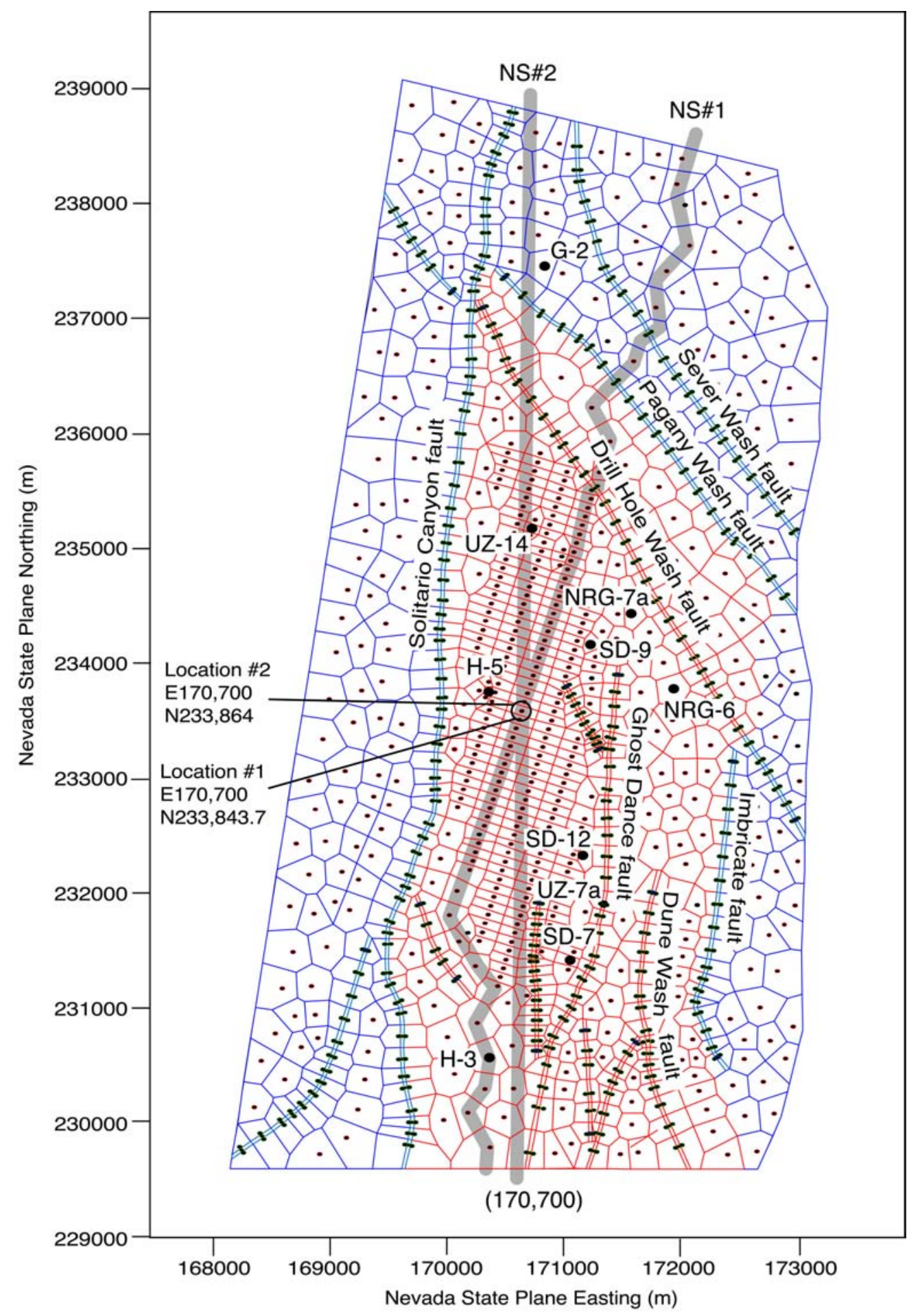

UZPMR3.12-3REV00

Figure 1. 


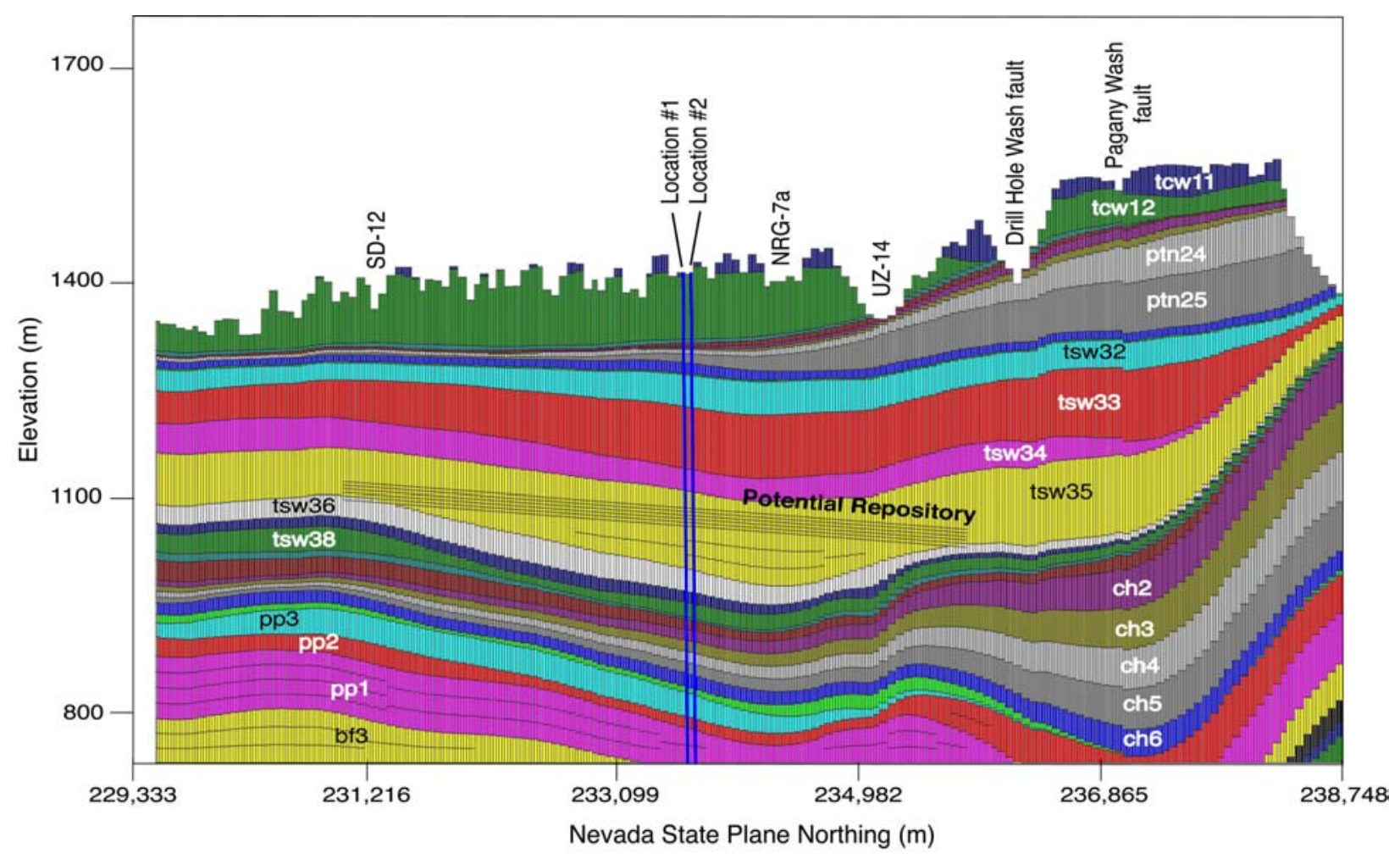

UZPMR3.12-4REVOO

Figure 2. 
(a) No Ventilation

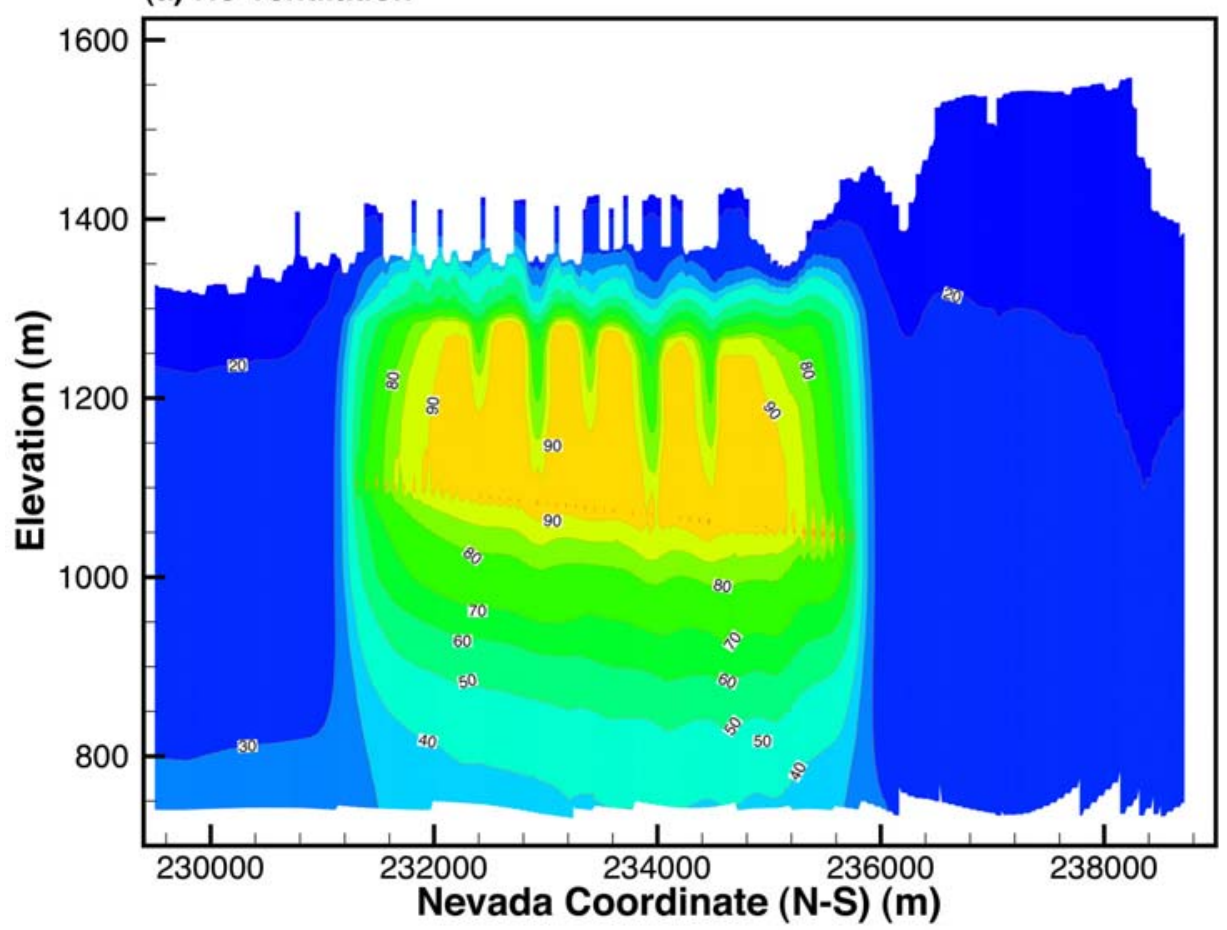

(b) With Ventilation

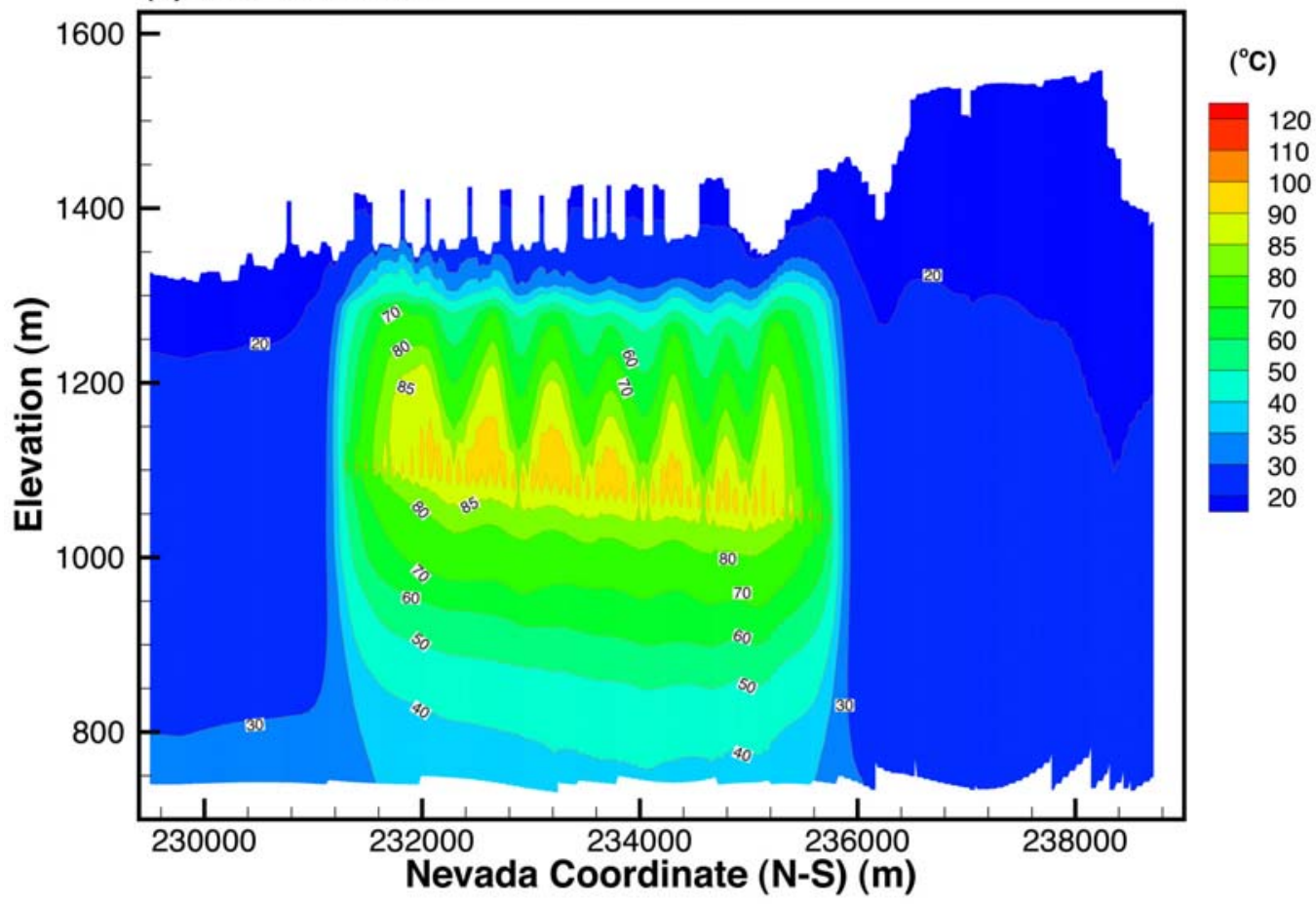

UZPMR3.12-5REV00

Figure 3. 
(a) No Ventilation

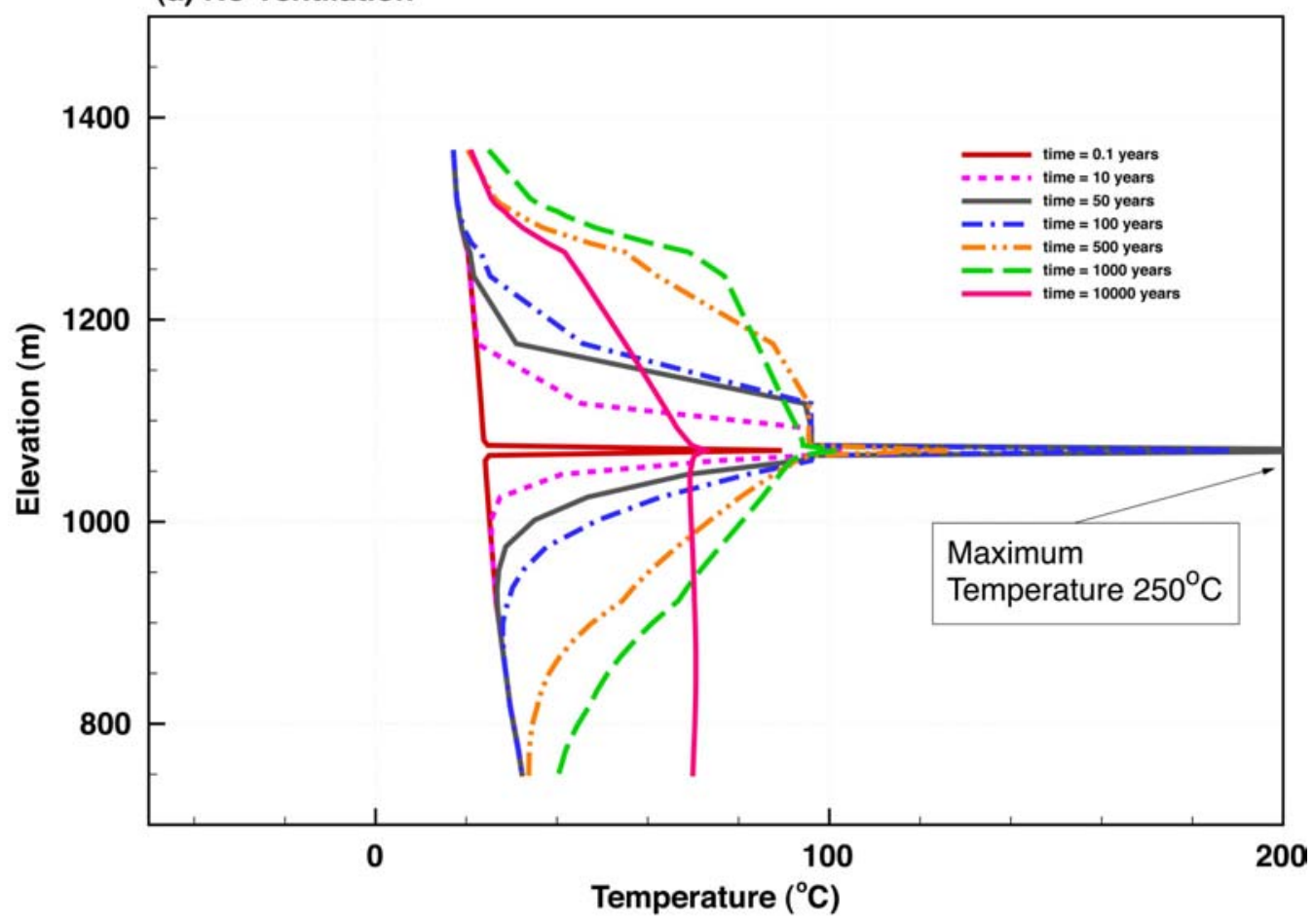

(b) With Ventilation



UZPMR3.12-6REVO0

Figure 4. 
(a) No Ventilation

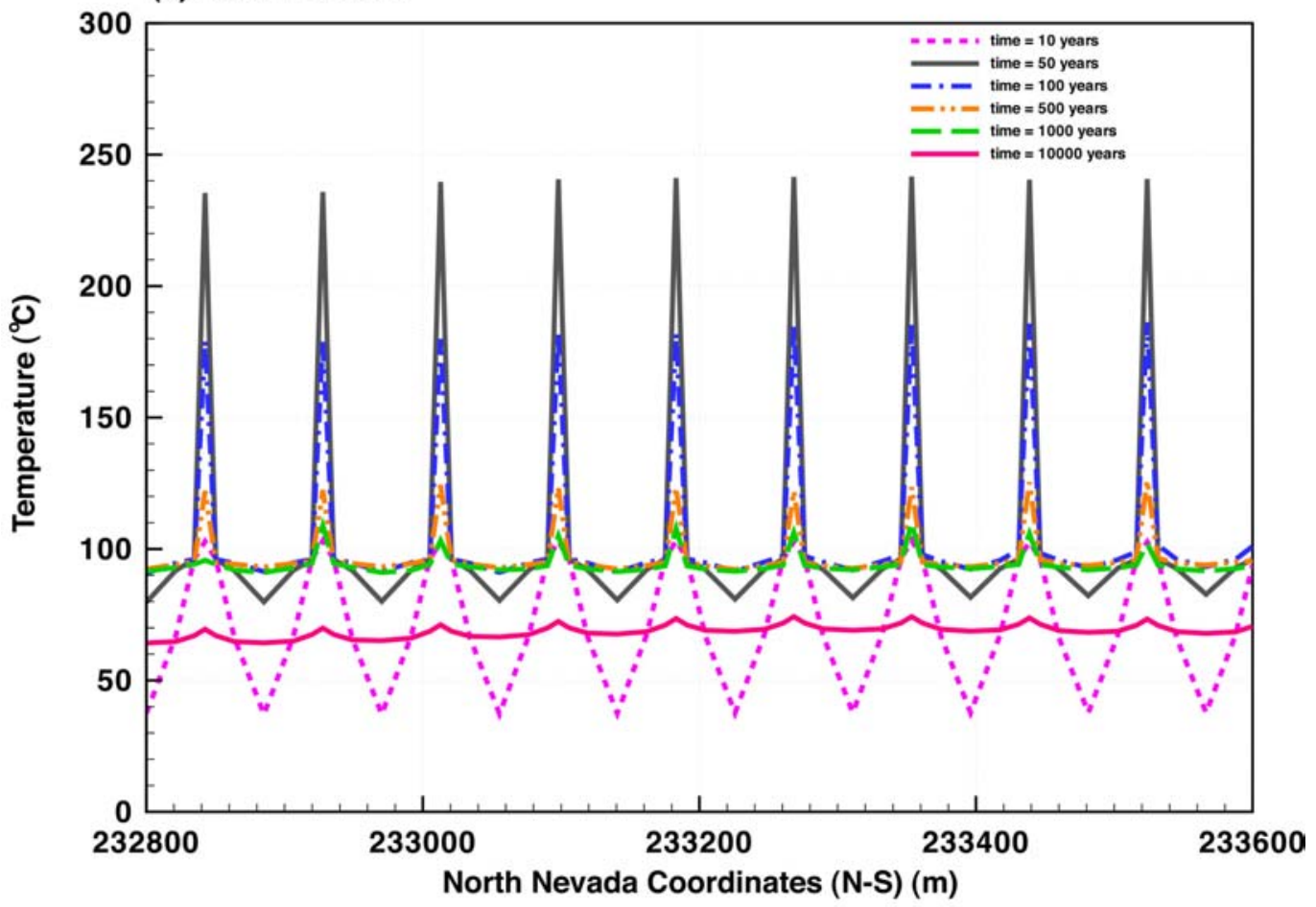

(b) With Ventilation

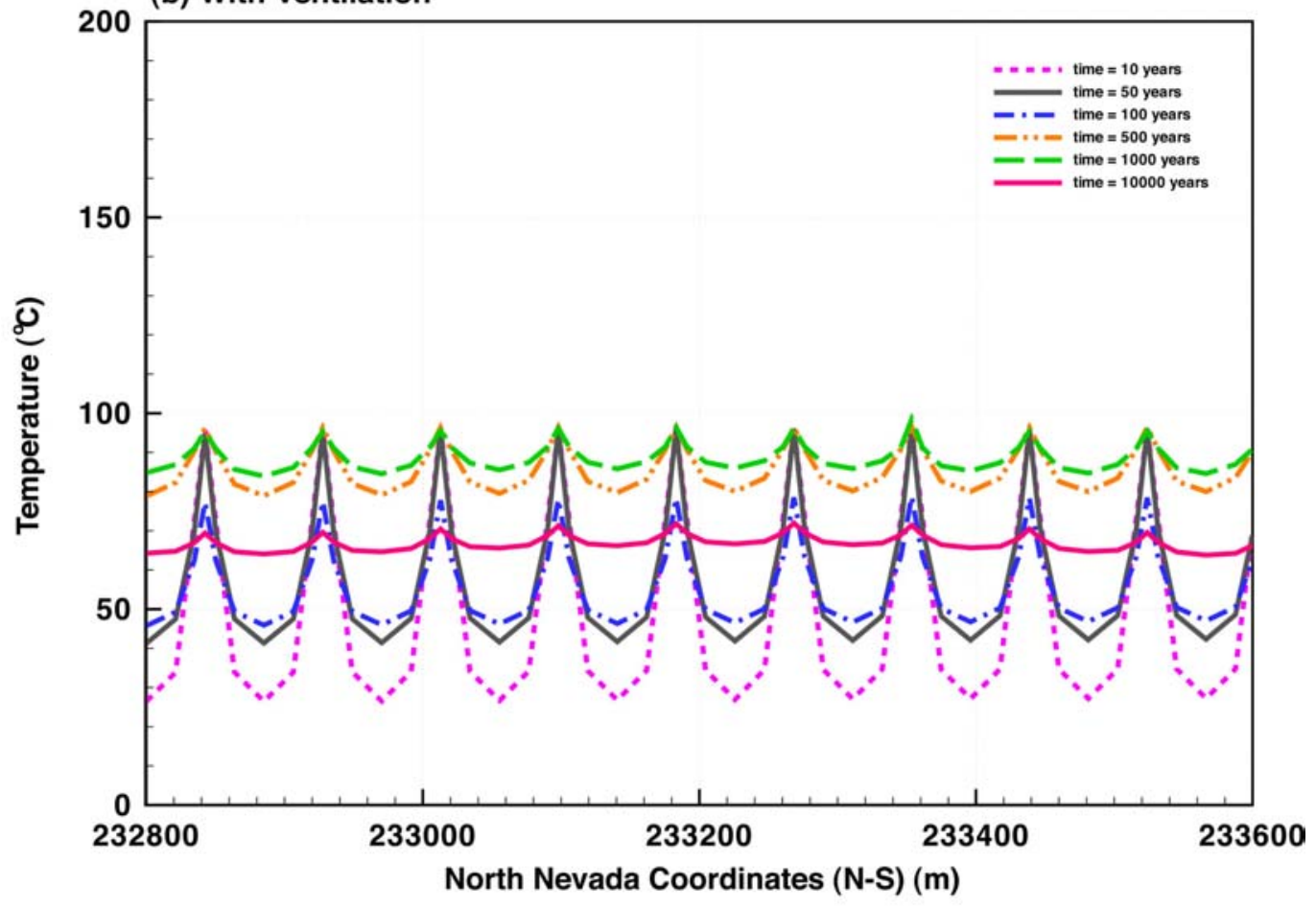

UZPMR3.12-7REV00

Figure 5. 
(a) No Ventilation

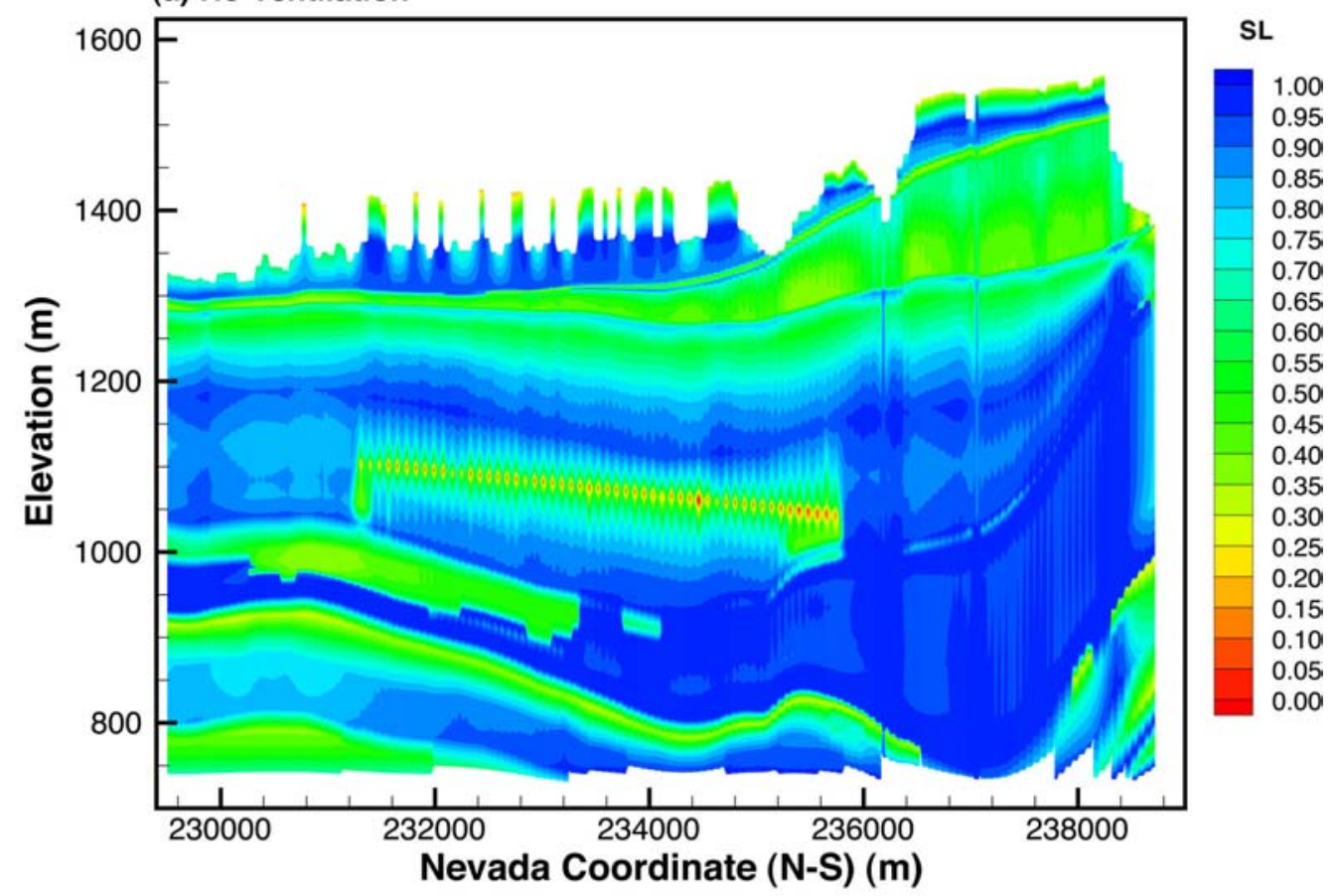

(b) With Ventilation

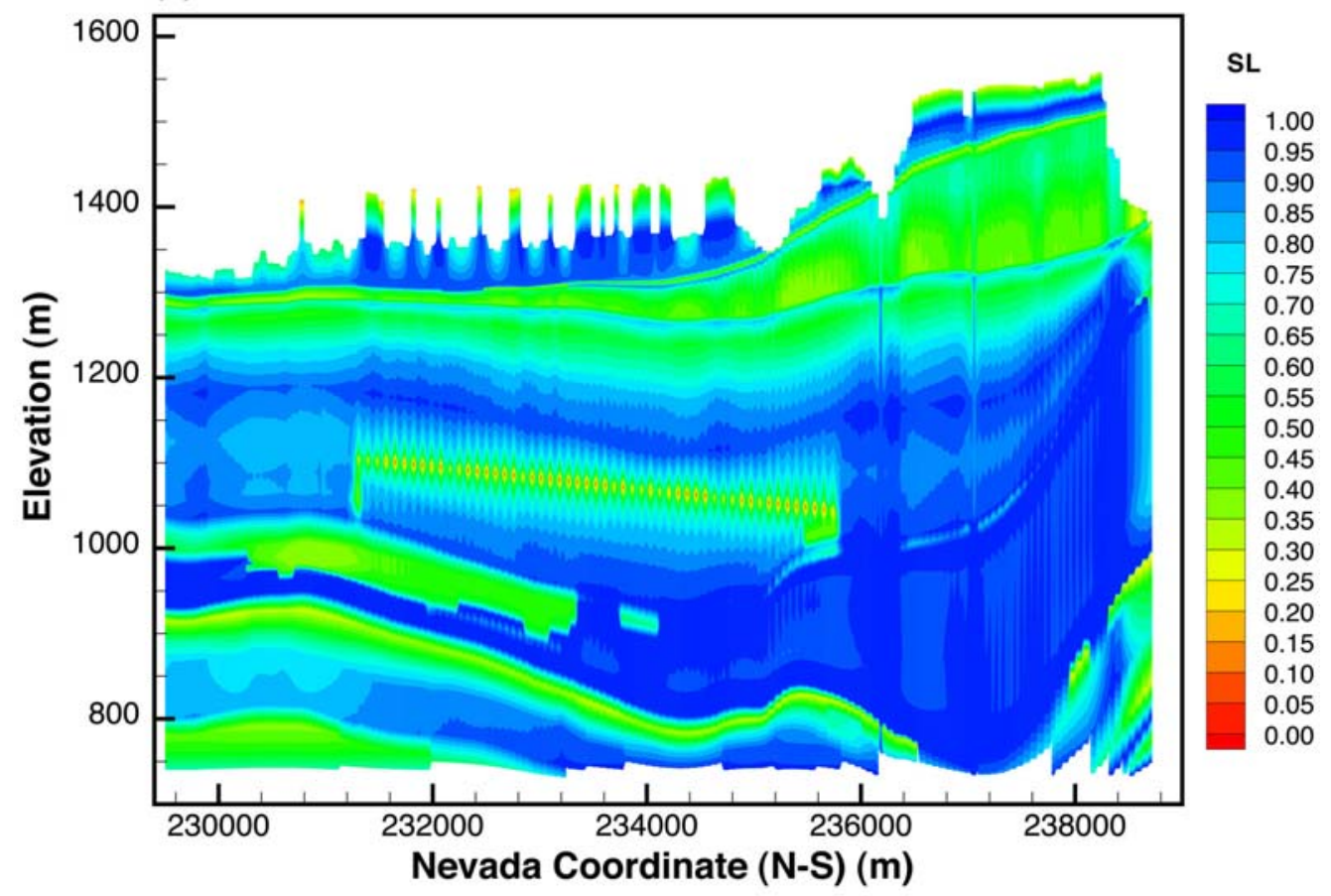

UZPMR3.12-8REV00

Figure 6. 
(a) No Ventilation

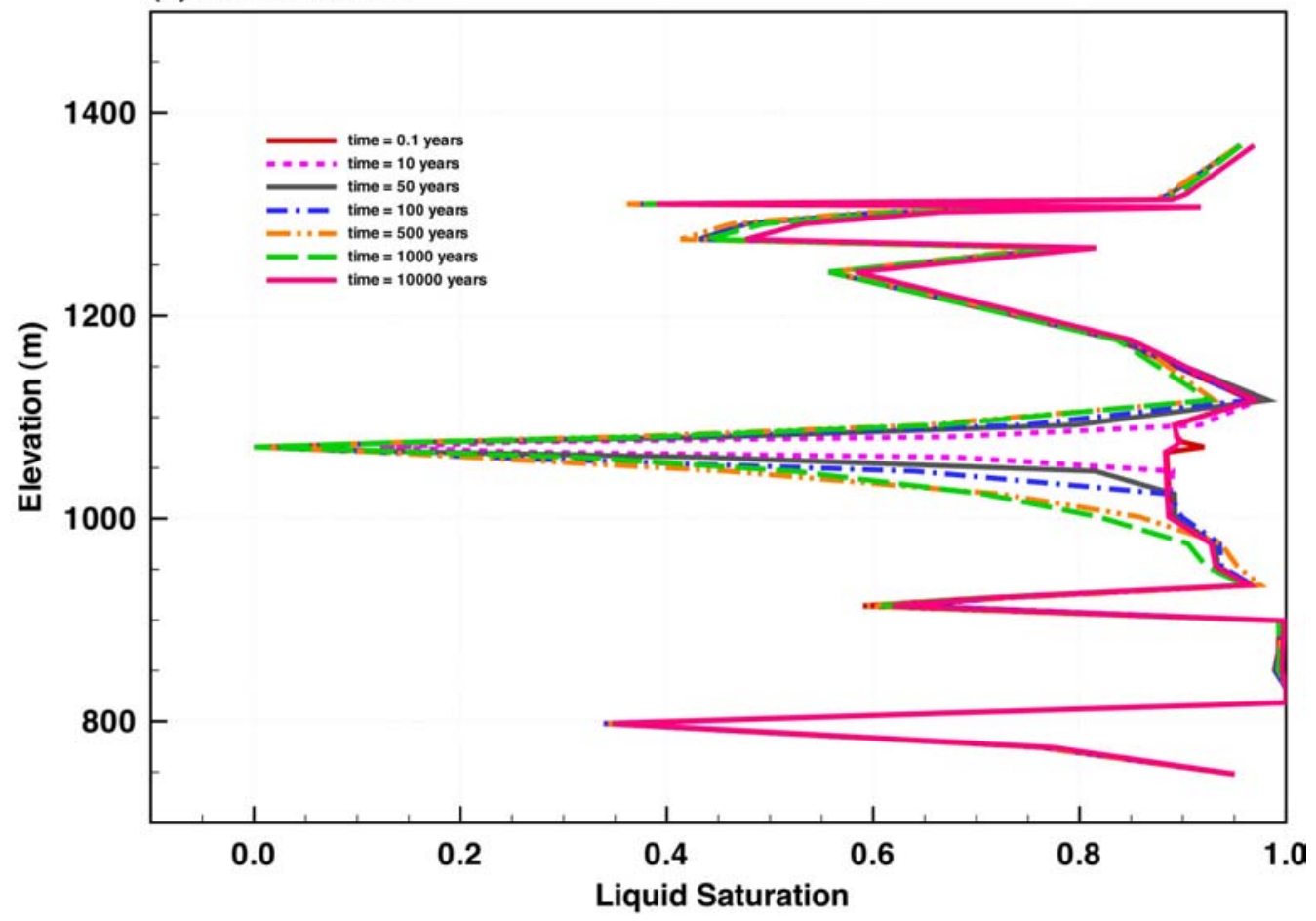

(b) With Ventilation

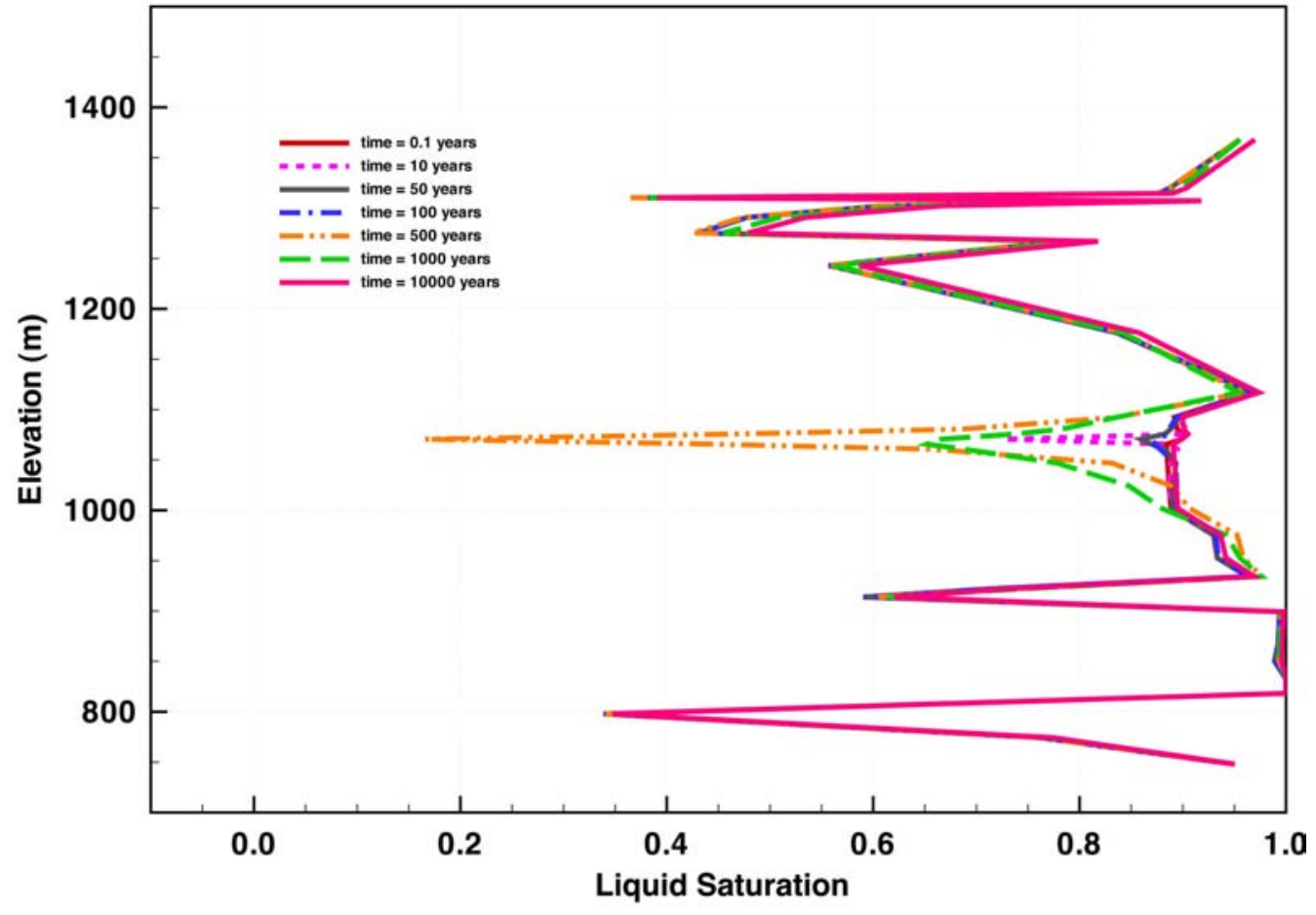

UZPMR3.12-9REVO0

Figure 7. 
(a) No Ventilation

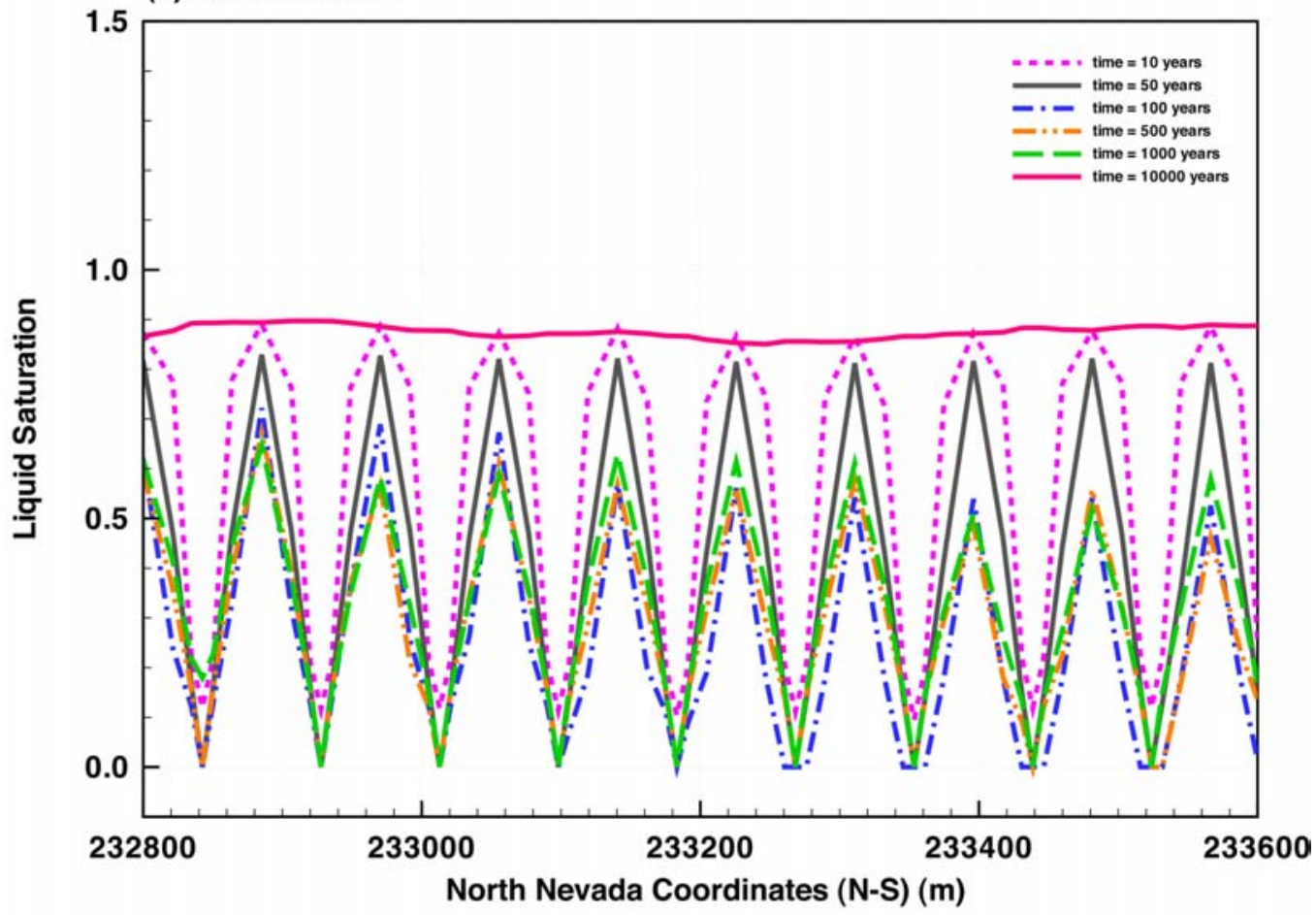

(b) With Ventilation

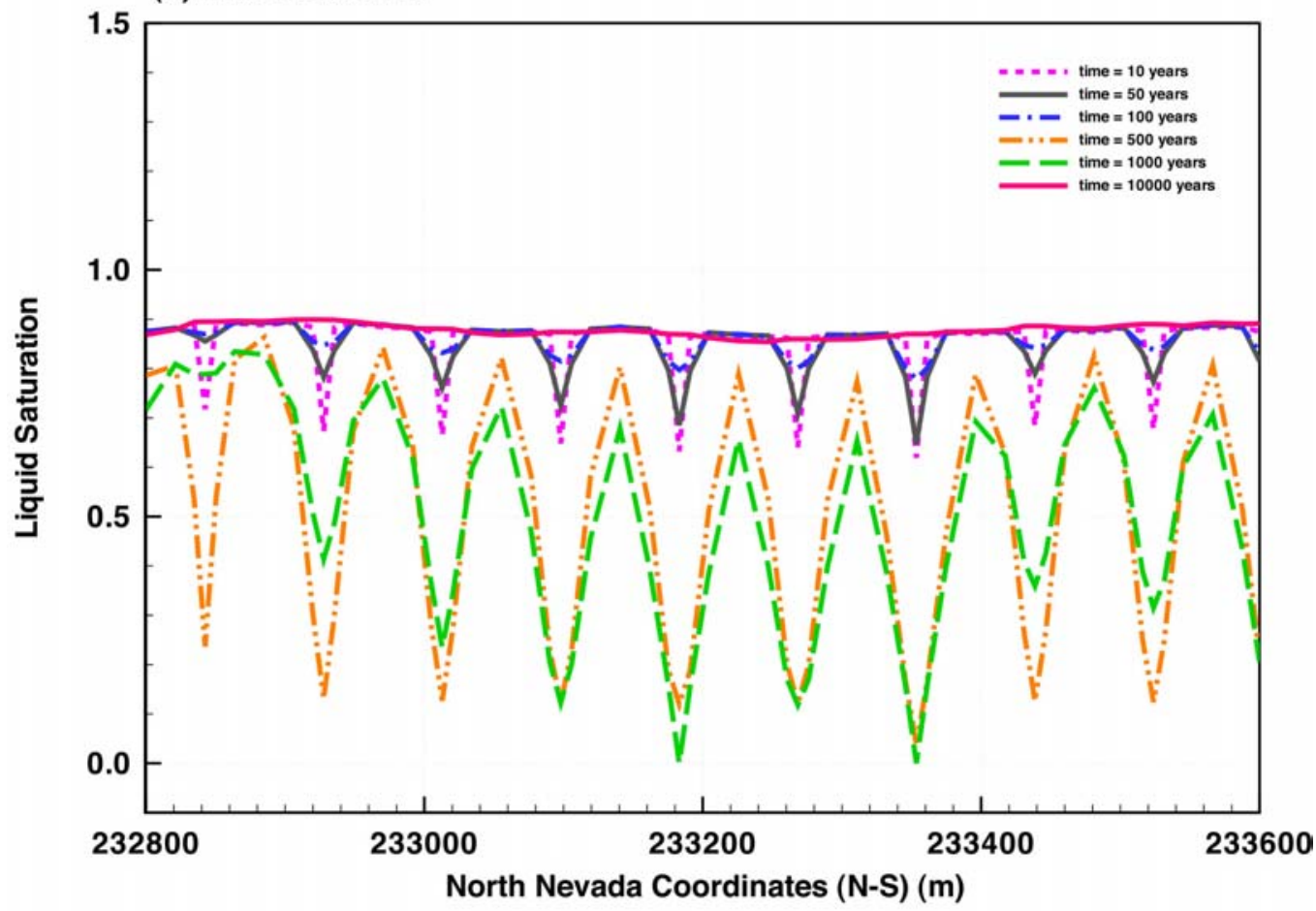

UZPMR3.12-10REV00

Figure 8. 
(a) No Ventilation

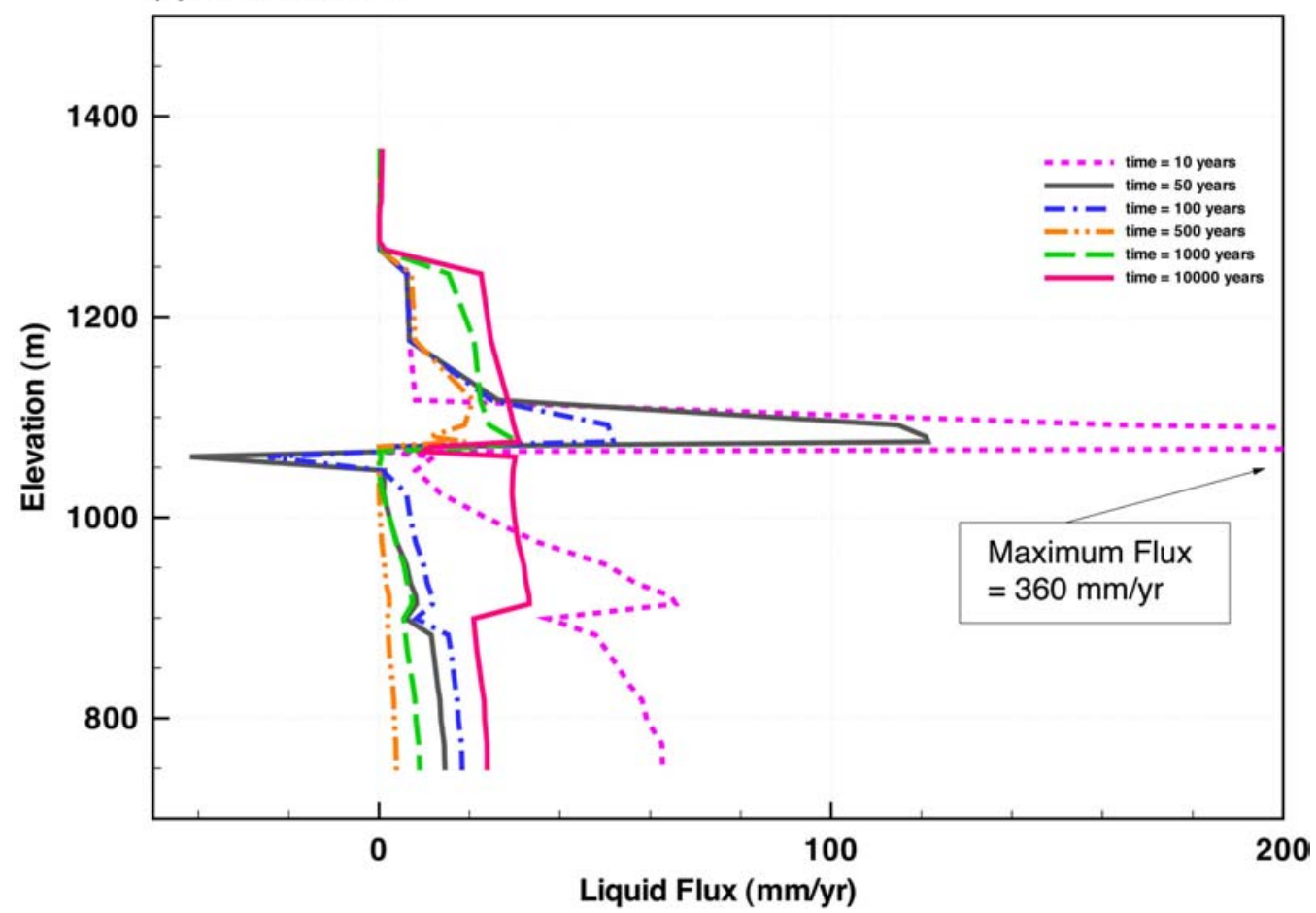

(b) With Ventilation

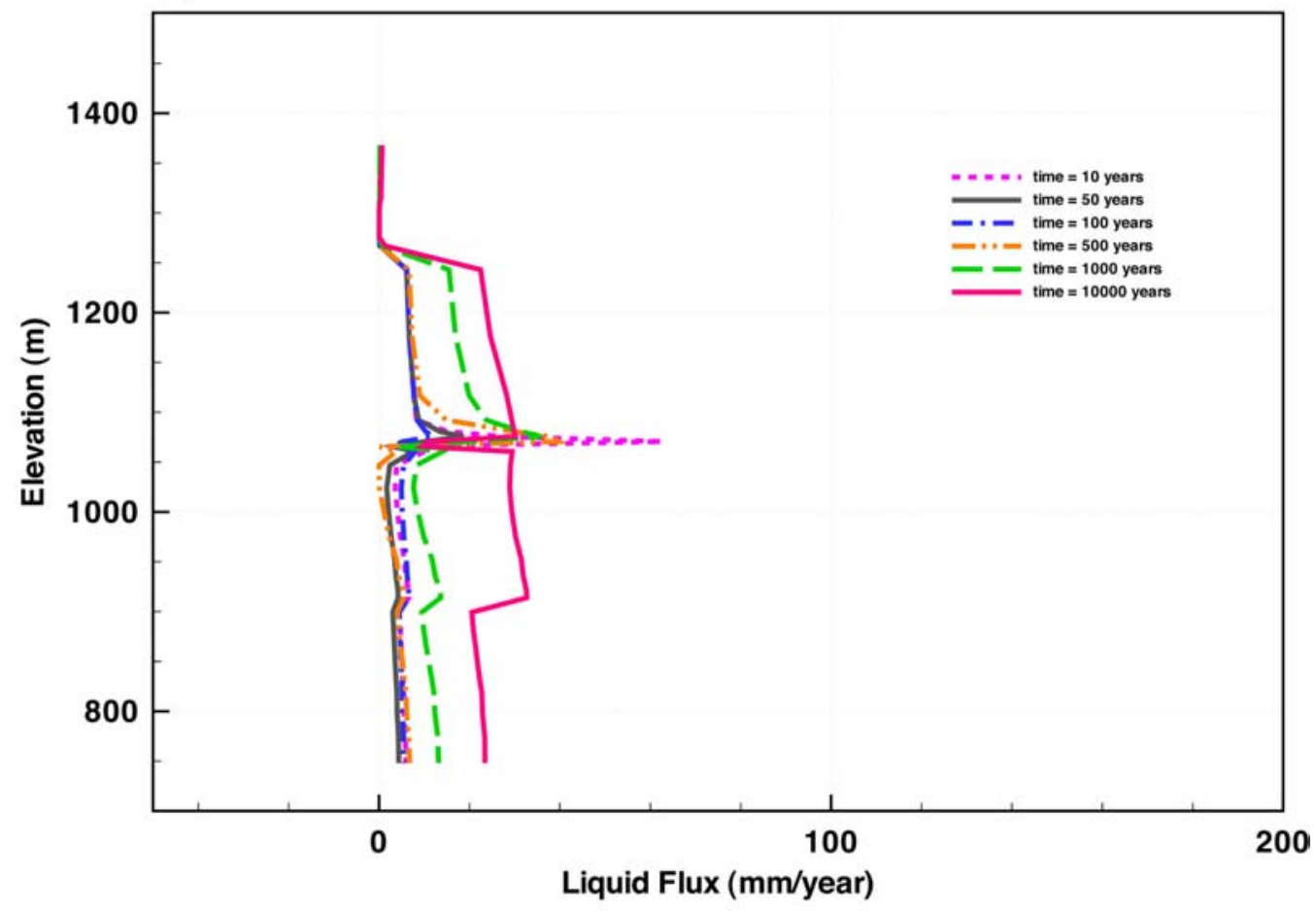

UZPMR3.12-11REVOO

Figure 9. 
(a) No Ventilation

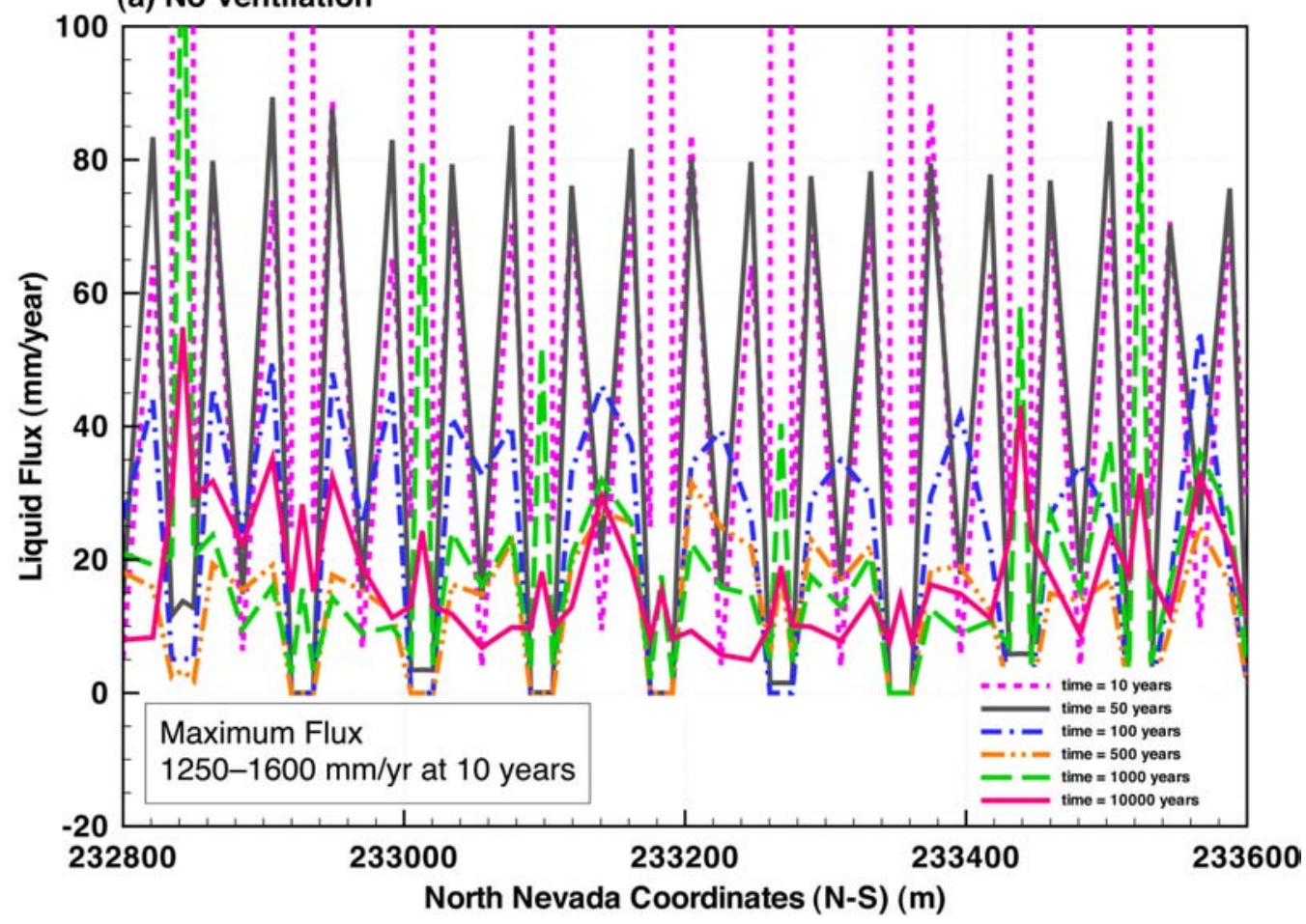

(b) With Ventilation

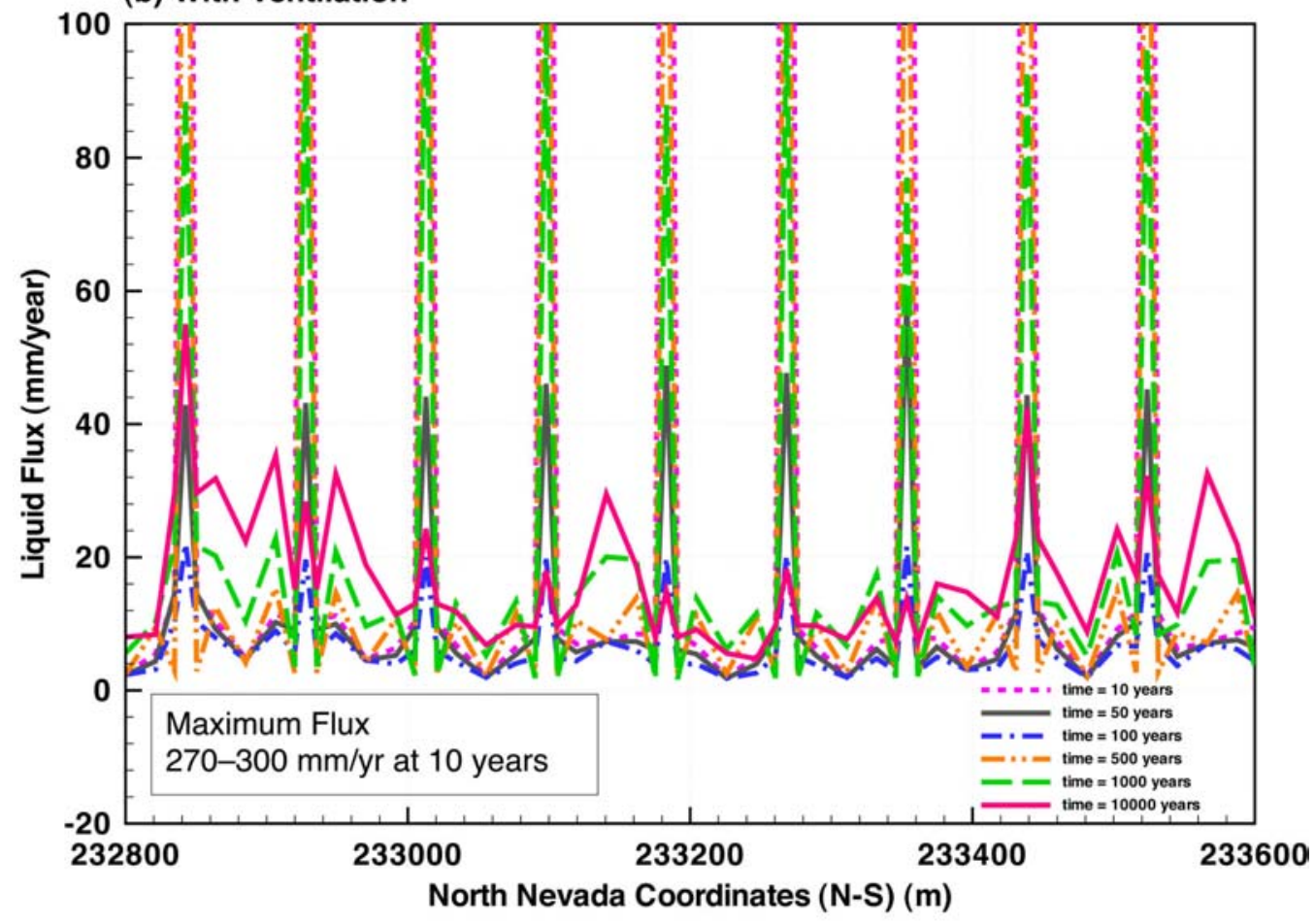

UZPMR3.12-12REV00

Figure 10. 